

\section{As políticas curriculares nacionais e a geografia nos currículos dos estados do Rio de Janeiro e de Goiás}

\section{Las políticas curriculares nacionales y la geografía en los currículos de los estados de Río de Janeiro y Goiás}

\section{National Curriculum Policies and Geography in the Curricula of the States of Rio de Janeiro and Goiás}

Eliana Marta Barbosa de Morais*

Ana Claudia Ramos Sacramento**

Karla Annyelly Teixeira de Oliveira ${ }^{* * *}$

Loçandra Borges de Moraes ${ }^{* * * *}$

\section{Resumo}

Nos últimos vinte anos se acirraram as discussões sobre o currículo da Geografia, em virtude da aprovação de uma série de documentos que têm normatizado e orientado os currículos dos cursos de formação de professores e das disciplinas escolares. Essas mudanças têm sido implementadas nas esferas municipais, estaduais e federais, seja nas instâncias públicas ou nas particulares, com diferentes ênfases. Este artigo busca refletir sobre os documentos curriculares oficiais direcionados à educação básica a partir da apresentação de resultados parciais de pesquisa desenvolvida na Rede Estadual de Educação dos Estados do Rio de Janeiro e de Goiás, com o fito de compreender o contexto da Educação Básica nacional e as diferentes formas de ensinar a disciplina de Geografia nesses estados.

\section{Palavras-chave}

currículo; Geografia escolar; rede estadual; Rio de Janeiro; Goiás. 


\section{Abstract}

Over the past two decades, discussions about the curriculum have been encouraged by the adoption of a series of documents that standardized and guided the curricula of teacher training courses and of school subjects. These changes have been implemented at a municipal, state and governmental level, both in public and private institutions, but with a different emphasis. This article seeks to reflect on the official curricula documents aimed at basic education based on the partial results of the research developed in the state network of Rio de Janeiro and Goiás, in order to understand the context of national basic education and the different ways of teaching geography in those states.

\section{Resumen}

En los últimos veinte años se han intensificado las discusiones sobre el currículo de geografía como resultado de la aprobación de una serie de documentos que han regulado y guiado los currículos de los cursos de formación de profesores y de las asignaturas escolares. Esos cambios han sido implementados a nivel municipal, estatal y federal, ya sea en la educación privada o en la pública, con distintos énfasis. Este artículo busca reflexionar sobre los documentos curriculares oficiales dirigidos a la educación básica por medio de la presentación de resultados parciales de la investigación realizada en la Red Estatal de Educación de los estados de Rio de Janeiro y Goiás con el reto de comprender el contexto de la educación básica nacional y las diferentes maneras de enseñar la asignatura de Geografía en dichos estados.

\section{Keywords}

Curriculum; school geography; state network; Rio de Janeiro; Goiás.

\section{Palabras clave}

Currículo; geografía escolar; red estatal; Rio de Janeiro; Goiás. 


\section{Introdução}

O currículo tem por objetivo orientar a construção do conhecimento escolar. É por meio dele que são conduzidas a teoria e a prática de todo o processo de ensino-aprendizagem que se desenvolve no ambiente escolar, culminando no tipo de formação ofertada e na que se almeja alcançar. Entendemos o currículo como um objeto dinâmico resultante da práxis de diferentes atores que o movimentam para a concretização de práticas pedagógicas direcionadas à construção de um determinado conhecimento escolar. Não se trata, portanto, de simples desenhos curriculares, mas, sim, de uma concepção, um projeto, da sociedade que se deseja construir.

Na construção de um currículo já estão imbricadas as relações de poder, de cultura e as ideologias de uma sociedade, uma vez que essas se constituem nos elementos fundamentais da construção das práticas cotidianas vivenciadas dentro e fora da escola. Portanto, o currículo estabelece uma organização que permite ou não o entendimento pleno do que é viver numa dada sociedade. Moreira e Silva $(2001$, p.7) contribuem com essa análise ao assim explicitarem:

O currículo é considerado um artefato social e cultural. Isso significa que ele é colocado na moldura mais ampla de suas determinações sociais, de sua história, de sua produção contextual [...]. O currículo está implicado em relações de poder, o currículo transmite visões sociais particulares e interessadas, o currículo produz identidades individuais e sociais particulares [...] ele tem uma história, vinculada às formas específicas e contingentes de organização da sociedade e da educação.

Ao se constituir, por si só, num documento que gera uma concepção ideológica de conhecimento, o currículo também produz uma forma de compreensão sobre um determinado contexto a partir das relações que se concretizam nas diversas maneiras de ler e compreender o que se apresenta em suas linhas e entrelinhas. $O$ currículo tem um caminho, um conjunto de relações vinculadas à sua história, constituindo diferentes histórias e identidades, tanto sociais como individuais.

Essas histórias são organizadas a partir de diferentes elementos que, por vezes, estão fora da escola, de acordo com os interesses do Estado, da economia e da política. Lopes e Macedo (2011) dialogam sobre isso ao dizerem que o currículo faz parte de uma conjuntura político-ideológica que está ancorada por toda uma estrutura construída ao longo de uma concepção global e neoliberal atual. Desse modo, o currículo se torna não só um objeto de poder, mas também uma forma de legitimar um conjunto de ações que produzem discursos e interpretações sobre a construção do conhecimento.

Cada contexto histórico caracteriza formas políticas e econômicas às quais interferem nas organizações curriculares de uma disciplina, bem como na escolha dos conceitos e conteúdos e na dinâmica escolar. Essas formas se referem a tradições que expressam as mudanças ocorridas de acordo com as necessidades do mundo de cada época, de sua cultura, de sua economia e, também, das expressões de concepções e de crenças dos sujeitos que produzem o currículo. Portanto, não é um processo neutro. Pode-se dizer que o currículo da Geografia também é um artefato social, ideológico, político e cultural que passou e vem passando por várias mudanças ao longo de sua trajetória (Rocha, 1997).

As mudanças pontuais no campo de uma disciplina específica, especialmente em termos de carga horária e do papel social atribuído aos seus conteúdos, resultam da macropolítica mundial da educação. Assim, questões referentes às políticas curriculares têm ganhado grandes proporções em todo o mundo, principalmente entre as décadas de 1980 e 1990, caracterizadas como um período de transformações na vida social, na tecnologia, nas relações internacionais. Como o próprio Ball (2004) afirma as políticas educacionais hoje têm de ser vistas sob a perspectiva regional e global, à quais está, cada vez mais, articulada às questões do comércio internacional.

Nesse sentido, são empreendidas constantemente reformas curriculares que incidem diretamente na requalificação do papel e da formação do professor, na configuração da matriz curricular, nos processos avaliativos, na elaboração do material didático, no cotidiano escolar, dentre outros. Essa requalificação com a intenção de moldar as práticas educacionais aos interesses econômicos tem buscado, nesta dinamicidade, a formação do "novo cidadão" para o mercado de trabalho e para o consumo.

No contexto atual, a partir de 1990, uma série de organismos internacionais vem intervindo no campo educação, criando novos parâmetros de discussões e de produção das políticas curriculares nos diversos países capitalistas. ${ }^{1}$ Esse movimento teve como marco essencial a realização da "Conferência Mundial de Educação para Todos", em Jomtien, na Tailândia, com o objetivo centrado na defesa da universalização da Educação Fundamental, com destaque na ampliação de oportunidades de ensino-aprendizagem para crianças, jovens e adultos. Como resultado dessa conferência, o governo brasileiro elaborou o Plano Decenal de Educação para Todos (1993-2003) que, dentre outras exigências, traz a necessidade da criação de parâmetros curriculares para o ensino obrigatório (Pereira, Santos, \& Leite, 2012).

Como expressão dessa demanda internacional pela estruturação dos currículos escolares é que no Brasil são produzidos os Parâmetros

1 Banco Mundial (BM), Organização das Nações Unidas para a Educação, Ciência e a Cultura (UNESCO), Fundo das Nações Unidas para a Infância (UNICEF), Programa das Nações Unidas para o Desenvolvimento (PNUD) e outros organismos internacionais. 
Curriculares Nacionais (PCNs), tendo como referências as antigas propostas curriculares de alguns estados brasileiros, o apoio de organismos internacionais e a assessoria do espanhol César Coll.

Nesse contexto, como o currículo nacional se configura como um parâmetro curricular, couberam às redes de ensino - estaduais, municipais e particulares - a tarefa de se basear nos PCNs e elaborar suas próprias propostas curriculares. Assim, muitos estados brasileiros investiram na produção de seus currículos. Tendo como referência os casos de Goiás e do Rio de Janeiro, questiona-se: como são esses currículos? Quais políticas públicas os fundamentam? Quem são os professores que fazem esse currículo cotidianamente? Como esses professores avaliam a concepção de Geografia veiculada por essas propostas curriculares?

Diante do exposto, objetiva-se no presente texto trazer alguns dados parciais da pesquisa "A disciplina de Geografia nos currículos estaduais de Goiás, Rio de Janeiro e São Paulo no contexto da Educação Básica Nacional", financiada pela FAPERJ de 2014-2015. Estrutura-se o texto em três tópicos. O primeiro trata dos documentos que regulamentam o currículo da educação básica brasileira com a intenção de ressaltar o papel de cada um deles na composição do currículo escolar. O segundo tópico trata dos currículos das redes estaduais de ensino do Rio de Janeiro e de Goiás com ênfase na caracterização dos professores de Geografia que atuam nesses currículos. E o último, por sua vez, ressalta o modo como os professores concebem a Geografia e os conteúdos geográficos presentes nas propostas curriculares desses dois estados.

\section{Política do Currículo: documentos que regulamentam o ensino escolar}

A discussão curricular, que legitima uma forma de condução da educação pública nacional e seus parâmetros, esteve presente no Brasil desde o período colonial até a república. Ao longo do tempo, diferentes leis contribuíram para dar uma dimensão nacional às políticas educacionais. Tais leis, específicas ou não da educação, subsidiam a construção de propostas curriculares; a organização e a operacionalização do currículo; a regulamentação da formação docente; a produção de materiais didáticos, entre outros. É a partir desse contexto que se discute o currículo tendo como referência a Constituição Federal (CF), a Lei de Diretrizes e Bases para Educação Nacional (LDB), as Diretrizes Curriculares Nacionais da Educação Básica (DCNs) e a Base Nacional Comum Curricular (BNCC).

A Constituição Federal (CF), finalizada em 1988, tem como objetivo assegurar garantias constitucionais para os cidadãos brasileiros a fim de promover a igualdade social. Nesse documento, especialmente em seu capítulo III, Seção I, algumas garantias legais foram estabelecidas para a educação. De certa maneira, a CF foi inovadora por definir pontos importantes para a manutenção e desenvolvimento da educação no país, como, por exemplo, a destinação para a educação de um percentual mínimo da receita da união, dos estados e dos municípios. Conforme o documento:

Art. 212. A União aplicará, anualmente, nunca menos de dezoito, e os Estados, o Distrito Federal e os Municípios vinte e cinco por cento, no mínimo, da receita resultante de impostos, compreendida a proveniente de transferências, na manutenção e desenvolvimento do ensino. (Constituição da República Federativa do Brasil, 1988).

No Artigo 205, ao afirmar que a educação é um direito do cidadão e um dever do Estado, a CF explicita o papel que este tem em prover e manter as escolas públicas, de forma a prestar um serviço educativo aos cidadãos brasileiros para cumprir uma das premissas do direito social. Assim como também é dever da família incentivar os filhos a estarem dentro da escola para se prepararem para o exercício de sua cidadania e para se qualificarem para o mercado de trabalho.

No Artigo 206 estão relacionados os princípios para a efetivação do ensino no país. Dentre eles destacam-se as questões da igualdade de condições para ter acesso e permanência na escola; liberdade de ensinar e aprender; pluralismo de ideias; gratuidade do ensino público; garantia à educação básica obrigatória e gratuita para a população de 4 a 17 anos e para aquela que não teve acesso ao ensino Fundamental e Médio na idade esperada.

Destacam-se, ainda, na CF os Artigos 210 e 211 . O primeiro garante que se elabore um documento que defina uma base de formação comum para os estudantes e com conteúdos de conhecimentos mínimos, sem descaracterizar os aspectos regionais e nacionais, bem como as diferentes dimensões culturais e artísticas. No segundo define-se que união, estados e municípios devem atuar de modo colaborativo na construção e gestão administrativa e pedagógica da educação.

Considerando a CF, a construção do currículo em diferentes escalas (nacional, estadual e municipal) leva em conta as concepções ideológicas, teórico-metodológicas, pedagógicas e administrativas que perpassam cada proposta curricular, trazendo em seu bojo uma concepção própria de construção do conhecimento. A seleção e análise desses artigos da CF evidenciam a necessidade de compreender a relação entre Educação, Currículo e Estado, uma vez que eles trazem os elementos centrais para a proposição de uma base curricular que vise garantir o direito de todos ao conhecimento escolar.

Se por um lado a CF traz elementos mais gerais de garantia à educação, a Lei de Diretrizes e Bases para Educação Nacional - LDB (Lei no 9.394, 1996) - explicita a estrutura de funcionamento da educação nacional, tanto básica como superior em suas diferentes modalidades. 
Aprovada em dezembro de 1996 com o número 9.394/96, a LDB traz importantes elementos para a gestão curricular da educação básica nacional. Ao longo de seus noventa e dois artigos, nos quais estão descritos os diferentes temas da educação brasileira, a lei estabelece uma série de normas de cunho científico e tecnológico que propiciam a produção do conhecimento e a organização social dos princípios para a cidadania.

Especificamente acerca do currículo na LDB, destacamos os Artigos 26 e 27 :

Art. 26. Os currículos do ensino fundamental e do ensino médio devem ter base nacional comum, a ser complementada, em cada sistema de ensino e em cada estabelecimento escolar, por uma parte diversificada, exigida pelas características regionais e locais da sociedade, da cultura, da economia e dos educandos. (Lei no 12.796, 2013).

$\S 1^{\circ}$. Os currículos a que se refere o caput devem abranger, obrigatoriamente, o estudo da língua portuguesa e da matemática, o conhecimento do mundo físico e natural e da realidade social e política, especialmente do Brasil. (Lei no 9.394, 1996, p. 11).

A composição e a qualificação dos conteúdos escolares a serem ensinados no Ensino Fundamental e Médio são definidas no Artigo 26. Assim, com o intuito de garantir uma base nacional comum, explicita-se que tais conteúdos devem ser compostos por conhecimentos gerais e também por conhecimentos regionais e locais, garantindo a especificidade da realidade dos alunos para a construção do conhecimento escolar. Na qualificação dos conteúdos escolares, além de Língua Portuguesa e Matemática, é possível notar a possibilidade de trabalhar com a Geografia na escola, pois também aparece no texto a previsão da abordagem do "conhecimento do mundo físico e natural e da realidade social e política especialmente do Brasil", ou seja, não está evidenciado que a disciplina Geografia deva aparecer no currículo, mas traz um indício, pois estes temas são abordados também pela ciência geográfica.

Ainda na qualificação dos conhecimentos escolares, em seu Artigo 27 a LDB ressalta a importância dos conhecimentos vinculados à formação de valores, posturas éticas voltadas para a cidadania e as orientações para o mercado de trabalho, conforme pode ser observado a seguir:

Art. 27. Os conteúdos curriculares da educação básica observarão, ainda, as seguintes diretrizes:

I - a difusão de valores fundamentais ao interesse social, aos direitos e deveres dos cidadãos, de respeito ao bem comum e à ordem democrática;

II - consideração das condições de escolaridade dos alunos em cada estabelecimento;

III - orientação para o trabalho;

IV - promoção do desporto educacional e apoio às práticas desportivas não-formais. (Lei no 9.394, 1996, p. 11).
A LDB, além de ser um documento que trata da carga horária e períodos para a realização do ensino, traz diretrizes que deverão perpassar a abordagem dada aos conteúdos escolares, como, por exemplo, os valores sociais e a promoção do desporto educacional.

Nota-se, portanto, nesses artigos, que a LDB trata do currículo e de sua importância para o ensino Fundamental e Médio como forma de estabelecer uma normatização em relação ao currículo e aos conteúdos e conceitos mínimos que devem fazer parte dos currículos escolares e, consequentemente, da prática docente.

Em consonância com a CF e com a LDB, o Conselho Nacional de Educação (CNE) elaborou as Diretrizes Curriculares Nacionais da Educação Básica (DCNs), que objetivam orientar o planejamento curricular das escolas e dos sistemas de ensino para a Educação Básica (Ministério da Educação, 2013). As DCNs também estabelecem que a educação é um direito do indivíduo e que a sua oferta é um dever do Estado e da família, especialmente quando define que o Ensino Fundamental deve ser público, gratuito e de qualidade, sem requisito de seleção.

Segundo as DCNs, a carga horária mínima anual do Ensino Fundamental regular deve ser de oitocentas horas-relógio, distribuídas em, pelo menos, duzentos dias de efetivo trabalho escolar ao longo de nove anos. O público-alvo dessa fase do ensino centra-se na população escolar com faixa etária entre seis e quatorze anos de idade e se estende também àqueles que, na idade própria, não tiveram condições de frequentá-lo.

De acordo com esse documento, o currículo do Ensino Fundamental é entendido como constituído pelas experiências escolares que se desdobram em torno do conhecimento, permeados pelas relações sociais, no qual se articulam as vivências e saberes dos alunos com os conhecimentos historicamente acumulados, de forma a construir a identidade dos estudantes. Em relação aos componentes curriculares obrigatórios do Ensino Fundamental, são citadas as seguintes áreas de conhecimento: Linguagens, Artes, Educação Física, Matemática, Ciências da Natureza e Ciências Humanas.

No caso do Ensino Médio, o documento estabelece quatro áreas do conhecimento: Linguagens, Matemática, Ciências da Natureza e Ciências Humanas. Indica também a necessidade de contextualizar e promover a interdisciplinaridade ou outras formas de articulação entre as diferentes áreas do saber. Nesse documento é explicitado que o currículo deve garantir a educação tecnológica básica; o conhecimento do processo histórico de transformação social e cultural; a língua portuguesa como instrumento de comunicação e acesso ao conhecimento e exercício de cidadania; as metodologias diferenciadas; o domínio de princípios científicos e tecnológicos e as formas contemporâneas de linguagem. Nesse conjunto, os componentes curriculares se assemelham aos do Ensino Fundamental. 
A forma de organização em tempos escolares do Ensino Médio pode ter vários formatos como: as séries anuais, os períodos semestrais, os ciclos, os módulos, entre outros. A duração mínima dessa fase do ensino deverá ser de três anos e a carga horária mínima de duas mil e quatrocentas horas, cabendo aos estados e aos municípios determinar a carga horária destinada a cada disciplina escolar. Assim, o currículo tem como parâmetro o conhecimento científico, que é organizado por áreas de conhecimento e por disciplinas escolares, como é o caso da Geografia na área das Ciências Humanas. Como exigência das DCNs para a educação básica, da LDB e do Plano Nacional de Educação, está em processo de elaboração, desde 2015, a proposta curricular intitulada Base Nacional Comum Curricular (BNCC).

A BNCC é um documento cujo princípio orientador é um projeto de nação, uma proposta de currículo, de sujeito, de aprendizagem e de sociedade que se quer constituir. A elaboração dessa proposta curricular tem utilizado como metodologia a realização de reuniões envolvendo diferentes instituições e sujeitos vinculados à educação básica como: o Conselho Nacional de Secretários de Educação (CONSED), a União Nacional dos Dirigentes Municipais de Educação (UNDIME), o Fórum Nacional dos Conselhos Estaduais de Educação (FNCE), a União Nacional dos Conselhos Municipais de Educação (UNCME), a União Brasileira dos Estudantes Secundaristas (UBES) e o Fórum Nacional de Educação (FNE). Além disso, estão sendo realizadas consultas a professores universitários e das escolas.

Na BNCC as áreas do conhecimento e seus respectivos componentes curriculares são: Linguagens (Língua Portuguesa, Língua Estrangeira Moderna, Artes, Educação Física), Matemática, Ciências da Natureza (Ciências, Biologia, Química e Física) e Ciências Humanas (Geografia, História, Filosofia, Sociologia e Ensino Religioso). Portanto, ao que parece, a disciplina Geografia ainda é um componente importante no currículo brasileiro, pois continua como uma disciplina escolar na Base Nacional Comum Curricular.

Os conteúdos das disciplinas escolares são enfatizados na BNCC pela delimitação dos objetivos da aprendizagem. Esse modo de organizar os conteúdos fez com que, no caso da Geografia, ela fosse apresentada de forma muito ampla. Assim, muitos conceitos e temas básicos dessa disciplina como: região, lugar, paisagem e território não foram abordados de forma a garantir a identidade geográfica, o que amplia as dificuldades do professor em construir conhecimentos geográficos escolares.

Ao avaliar a primeira versão da BNCC, Castellar (2015) argumenta que o conhecimento geográfico está organizado em um conjunto de objetivos que não trazem avanços significativos para a aprendizagem, pois são muito amplos e, por isso, não possibilitam a "progressão" das sequências cognitivas. Além disso, menciona que os conteúdos e conceitos foram descaracterizados das discussões próprias da ciência, como é o caso do conteúdo de Cartografia, que desapareceu do currículo. Cabe destacar que no processo de elaboração da BNCC essa primeira versão do documento foi disponibilizada para avaliação crítica da sociedade em geral, da comunidade escolar e também por especialistas de cada disciplina. Sem entrar no mérito sobre o modo como esse debate foi realizado, ressalta-se que a segunda versão da matriz curricular da Geografia apresentou mudanças substanciais em relação à primeira. Assim, a cartografia, por exemplo, passou a aparecer como conteúdo explícito nos anos iniciais e finais do Ensino Fundamental, exceto no sétimo ano. Além disso, o lugar de vivência do aluno também aparece como uma referência para ser analisado à luz dos conceitos centrais de cada ano escolar. Ademais, os conceitos de escala, rede e o incentivo ao uso de diferentes linguagens também integram o rol de objetivos que compõem a matriz curricular.

O objetivo da BNCC, conforme explicitado pelo MEC, é desenvolver o processo de aprendizagem dos estudantes na Educação Básica, de modo a garantir o respeito de ensinar e aprender a todos, sem discriminação. Acerca disso assinala Cossio (2014, p. 1579):

A justificativa da proposta de um currículo nacional está amparada, de acordo com seus defensores - sobretudo aqueles vinculados ao empresariado brasileiro, como é o caso dos movimentos “Todos pela Educação", "Fundação Lemann”, "Itaú Social”, "Fundação Ayrton Senna", entre outros -, na redução das desigualdades regionais, garantindo o direito à aprendizagem. Há a argumentação de que quanto maior é a vulnerabilidade em que estão inseridos os alunos, menor é a sua aprendizagem, quando justamente ela deveria ser assegurada para quebrar o ciclo de exclusão e pobreza a que esses alunos estão submetidos.

Nessa mesma direção, Macedo (2014) chama a atenção não só para os agentes públicos, mas também para os privados que fazem parte de grandes empresas, destacando que a constituição de um currículo nacional é legítima, mas tem outras implicações que estão voltadas para atender interesses capitalistas comprometidos com a formação do cidadão consumista, conforme pode ser observado na citação a seguir:

[...] entre os sentidos de BNCC que circulam no debate, há quatro mais frequentes: conteúdos [poderosos, socialmente elaborados]; direitos de aprendizagem [direitos e objetivos de aprendizagem e desenvolvimento]; expectativa de aprendizagem; e padrões de avaliação. Tais significantes parecem se assentar sobre distintas concepções de educação e currículo em luta por hegemonia no atual debate sobre BNCC. (Macedo, 2014, pp. 1544-1545).

Enfim, esse documento direcionará as diferentes fases da escolaridade, a organização do sistema avaliativo e também será um dos pontos estratégicos que promoverão ações direcionadas a educadores, estudantes e gestores escolares. Portanto, a BNCC impactará na formação inicial e continuada dos docentes. Além disso, servirá de base para outros currículos, 
ou seja, ela será a base comum sob a qual os estados e municípios irão elaborar suas novas propostas curriculares. Esse currículo também é a principal referência de conteúdos científicos para o Ensino Médio que está em processo de reforma no ano de 2016, por meio da Medida Provisória 746 de $2016 .^{2}$

Os atuais currículos escolares dos estados brasileiros, ainda que tenham sido elaborados tendo como referência as DCNs para a educação básica, a LDB, o Plano Nacional de Educação e os Parâmetros Curriculares Nacionais (PCNs), possuem vários elementos daquele contexto que continuam válidos para a reflexão sobre o currículo escolar na atualidade. Nesse cenário, os próximos tópicos tratam do perfil e das concepções dos professores de Geografia que ensinam no âmbito dessas referências curriculares, especialmente dos currículos dos estados do Rio de Janeiro e de Goiás.

\section{Professores de Geografia que atuam nos currículos das redes estaduais de ensino do Rio de Janeiro e de Goiás}

Para compreender melhor uma proposta curricular torna-se relevante entender o contexto político de sua elaboração, conforme apresentado no tópico anterior, conhecer a proposta curricular em si e, principalmente, conhecer os professores que cotidianamente lidam com esses documentos.

Os estados brasileiros, para atingir as exigências dos documentos legais nacionais - CF, LDB e das DCNs - assim como dos órgãos internacionais, buscaram adaptar-se à realidade não só educacional, mas econômica e cultural. Desse modo, a criação do currículo carioca, assim como o goiano, não está associada apenas às questões educacionais, mas também às mudanças econômicas e políticas situadas nas esferas mundial, nacional e local.

No Estado do Rio de Janeiro, dentro do que se denomina atualmente "Currículo Mínimo", as reorientações curriculares estão presentes desde 2005. Essa reorientação foi realizada de acordo com as estruturas político-econômicas de cunho neoliberal e com os PCNs. A reorientação foi implementada a partir da seriação e por blocos bimestrais, ou seja, eixos

2 O cenário educacional brasileiro no ano de 2016, marcado pela crise política, tem deixado explicita a presença da ação e dos poderes dos diferentes sujeitos que atuam na construção de um projeto curricular. Nesse cenário, a CF e a LDB estão sendo profundamente alteradas pela Medida Provisória 746/2016 (reforma do Ensino Médio, que altera carga horária e estrutura organizacional), pelo Projeto de Lei 193 de 2016 (programa escola sem partido, que defende a neutralidade política, ideológica e religiosa) e pela PEC 55 de 2016 (que congela o investimento público em educação e outras despesas primárias do país por vinte anos). Assim, o Brasil vive um período de intensas manifestações políticas por estudantes e docentes do ensino básico e superior que se posicionam de modo contrário a esses projetos. Esse contexto, por si só, merece um artigo à parte. temáticos nos quais os professores focalizam os conteúdos específicos. Para cada bimestre é apresentada uma série de habilidades e de competências a serem desenvolvidas (Ferreira, 2009).

Criado em 2011 e reformulado em 2012, o Currículo Mínimo apresenta os conteúdos e os conceitos que os professores devem ensinar para que os estudantes possam realizar as avaliações externas e internas. Esse documento foi coordenado por professores de universidades situadas no estado do Rio de Janeiro e contou com o auxílio de uma equipe de professores da educação básica da rede estadual, mediante a solicitação de sugestões a respeito do currículo em reuniões presenciais e a distância.

No Estado de Goiás, a elaboração do currículo iniciou-se em 2004, passou por uma publicação preliminar em 2007 e teve seu auge em 2013, com a publicação e instituição do "Currículo Referência da Rede Estadual de Goiás: versão experimental” para toda a Educação Básica. Nesse documento o tempo escolar é organizado em torno dos bimestres letivos, para os quais são apresentadas as expectativas de aprendizagem, os eixos temáticos e os conteúdos geográficos a serem desenvolvidos e ensinados em cada bimestre (Sacramento, Morais, Oliveira \& Moraes, 2015). Em Goiás, o processo de elaboração curricular coordenado pela Secretaria de Estado de Educação também estabeleceu um diálogo com os professores da Universidade e da escola.

Quem são os professores de Geografia que trabalham com esses currículos? Como eles avaliam a Geografia presente nesses documentos? Para responder a esses questionamentos contou-se com o apoio dos docentes de Geografia que atuam em escolas estaduais do Rio de Janeiro e de Goiás, que gentilmente responderam aos questionários propostos pela pesquisa.

No Rio de Janeiro foram aplicados trinta e quatro questionários, dos quais vinte e quatro dos respondentes eram do sexo feminino e dez do sexo masculino, com média de idade entre 26 e 61 anos. A abrangência da pesquisa incluiu oito municípios da Região Metropolitana do Rio (Rio de Janeiro, São Gonçalo, Belford Roxo, Niterói, Rio Bonito, São João do Miriti, Itaboraí, Queimados e Nova Iguaçu); um município da região Serrana (Nova Friburgo); três das Baixadas Litorâneas (Rio das Ostras, Iguaba Grande e Casimiro de Abreu); e um da região dos Lagos (Cabo Frio) (Figura 1).

No Estado de Goiás foram aplicados quarenta e quatro questionários, dos quais vinte e seis dos professores são do sexo feminino e dezoito do masculino, com idades entre 21 e 62 anos. A área da pesquisa envolveu três municípios da Região Metropolitana de Goiânia (Goiânia, Hidrolândia e Senador Canedo); um município do Centro Goiano (Anápolis); um do Sul Goiano (Caldas Novas) e um do Noroeste Goiano (Goiás) (Figura 2).

Os professores foram contatados de formas distintas no Rio de Janeiro e em Goiás. No Rio de Janeiro, eles responderam ao questionário via 
e-mail ou durante visitas às escolas. Em Goiás, todas as entrevistas foram realizadas presencialmente, em escolas ou em outros locais indicados pelos professores, como exemplo a própria universidade. No questionário havia questões relativas à formação, atividade profissional e sobre o currículo do estado em que o professor lecionava.

No Rio de Janeiro, todos os professores entrevistados têm licenciatura em Geografia, concluída entre 1993 e 2013. Desses, vinte e três professores estudaram em universidades públicas, principalmente nas seguintes instituições: Universidade Estadual do Rio de Janeiro (UERJ-São Gonçalo) e na Universidade Federal Fluminense (UFF-Niterói). Além disso, cinco professores se formaram em bacharelado. Em relação à formação continuada, vinte e oito fizeram pós-graduação lato sensu em diferentes instituições, incluindo públicas e privadas; sete concluíram o mestrado em instituição pública; e dois estão cursando o mestrado.

Quanto aos professores do Estado de Goiás, quarenta fizeram graduação em Geografia, um em Ciências Sociais e três em História, tendo concluído a graduação entre os anos 1982 e 2015. A maior parte dos professores formou-se em instituições públicas, com destaque para a Universidade Estadual de Goiás e a Universidade Federal de Goiás. Em relação à formação continuada, trinta e dois fizeram pós-graduação lato sensu e oito professores cursaram mestrado, sendo que apenas um mestrado foi feito em universidade privada.

A formação inicial e continuada dos professores é uma forma de identificar algumas características gerais de como construíram suas profissões. É importante compreender a relevância dessa formação para a prática cotidiana na sala de aula e a sua influência na busca de novos conhecimentos, impactando diretamente o trabalho do professor.

Esses aspectos são apontados por Callai (2006) ao explicitar que os conhecimentos dos professores são caracterizados pelo conhecimento científico, resultado dos conteúdos específicos da disciplinar escolar, e pelos conhecimentos técnicos que podem ser aqueles caracterizados pela prática que se expressam em determinadas habilidades adequadas ao exercício profissional. Durante a formação inicial, a compreensão dos conceitos e conteúdos geográficos básicos, associada aos conceitos e conteúdos pedagógicos, são importantes referências na reflexão de uma educação geográfica desses professores. Soma-se a esses conhecimentos, que visam qualificar a prática docente no cotidiano do seu trabalho,

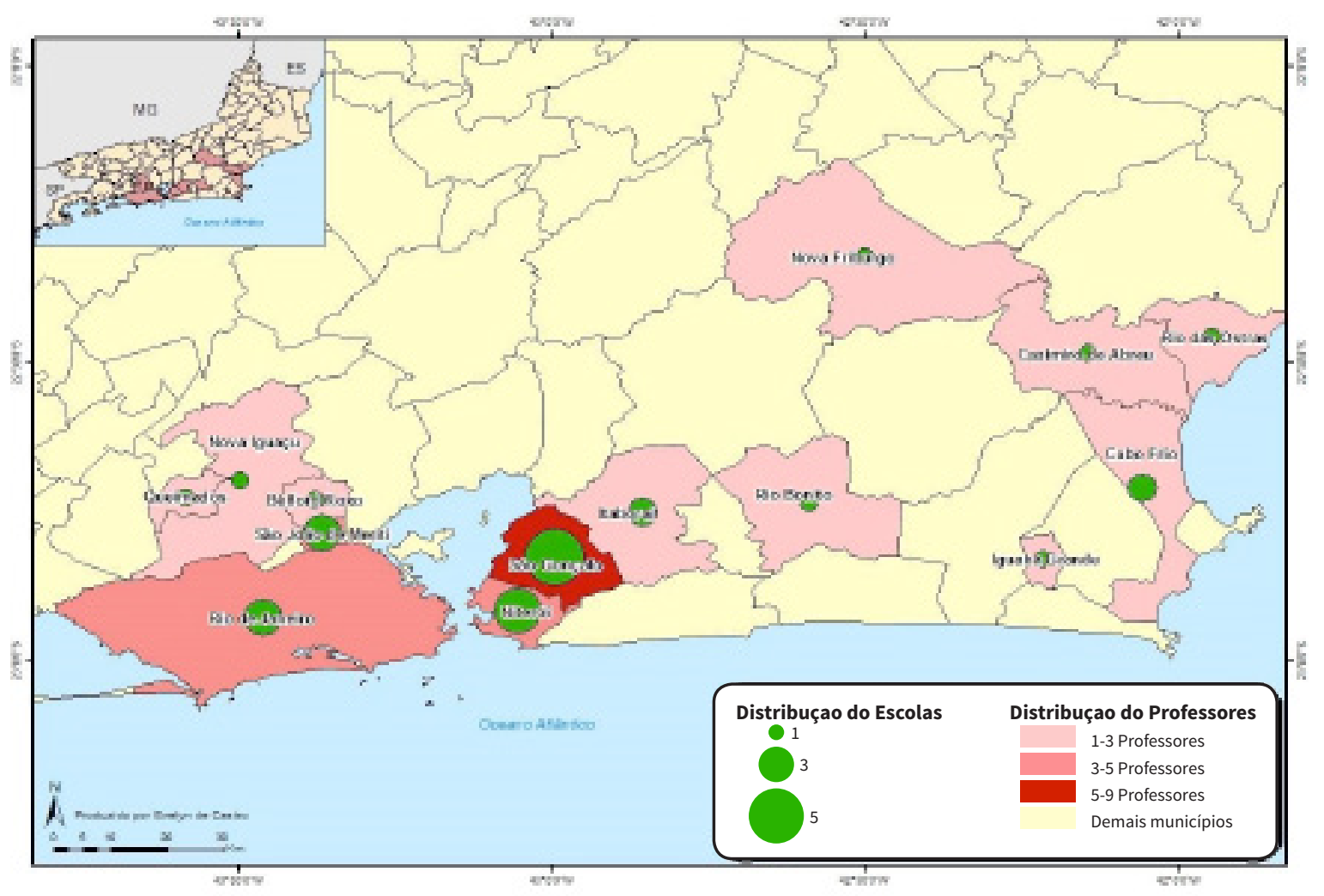

Figura 1. Distribuição de escolas dos professores entrevistados no Rio de Janeiro, 2015-2016. 
a experiência, tendo como uma de suas referências o tempo de serviço. Também são importantes a carga horária de trabalho semanal e os níveis de ensino em que os professores lecionam.

No Rio de Janeiro, os professores possuem entre dois e trinta anos de experiência no ensino básico. Desses, dezenove professores têm até dez anos de profissão; treze têm entre onze e vinte anos; e dois possuem experiência entre vinte um e trinta anos. Em relação à quantidade de escolas onde lecionam, vinte e dois professores têm pelo menos dois cargos, sendo que a maior parte com vínculo nas redes estadual e municipal (19 docentes). A maior parte dos professores pesquisados (32) é de funcionários públicos efetivos do Estado. Em relação à carga horária, a maioria trabalha até 30 horas semanais (22), depois vêm os que atuam entre 31 e 40 horas semanais (7) e, por fim, os que lecionam de 41 a 50 horas (3) e mais de 50 horas (2). A grande parte dos docentes leciona (22) nos anos finais do Ensino Fundamental e no Ensino Médio.

Os professores de Goiás pesquisados possuem entre dois meses e trinta e um anos de experiência na educação básica, o que possibilita visualizar diferentes momentos da carreira docente. Dezoito professores possuem até dez anos de profissão, dezenove têm entre onze e vinte anos de trabalho e sete possuem mais de vinte e um anos de experiência. Em relação à quantidade de escolas onde trabalham, trinta e dois lecionam apenas na rede estadual de ensino, nove professores trabalham em duas redes, incluindo a municipal ou a privada, e dois em três redes de ensino (estadual, municipal e privada). Sobre o vínculo de trabalho, trinta e três professores são efetivos, dez são contratados temporariamente e um não respondeu a esta questão. A maior parte dos professores (20) trabalha semanalmente com a carga horária de 32 a 40 horas, depois vêm os professores que atuam com carga horária de até 30 horas (10), na sequência aqueles que lecionam 60 horas (7) e, por fim, aqueles que possuem carga horária de 42 a 45 horas.

Em relação ao tempo de profissão, para Huberman (1995), o desenvolvimento profissional e didático do professor é um processo. Sendo assim, é necessário que ele se desenvolva, amadureça, vivencie certas situações de sua vida profissional na sala de aula, o que só se adquire ao longo do tempo. 0 tempo de trabalho mostra as diferentes relações estabelecidas pelos professores com o universo escolar, com as tendências educacionais e as experiências que são manifestadas a partir

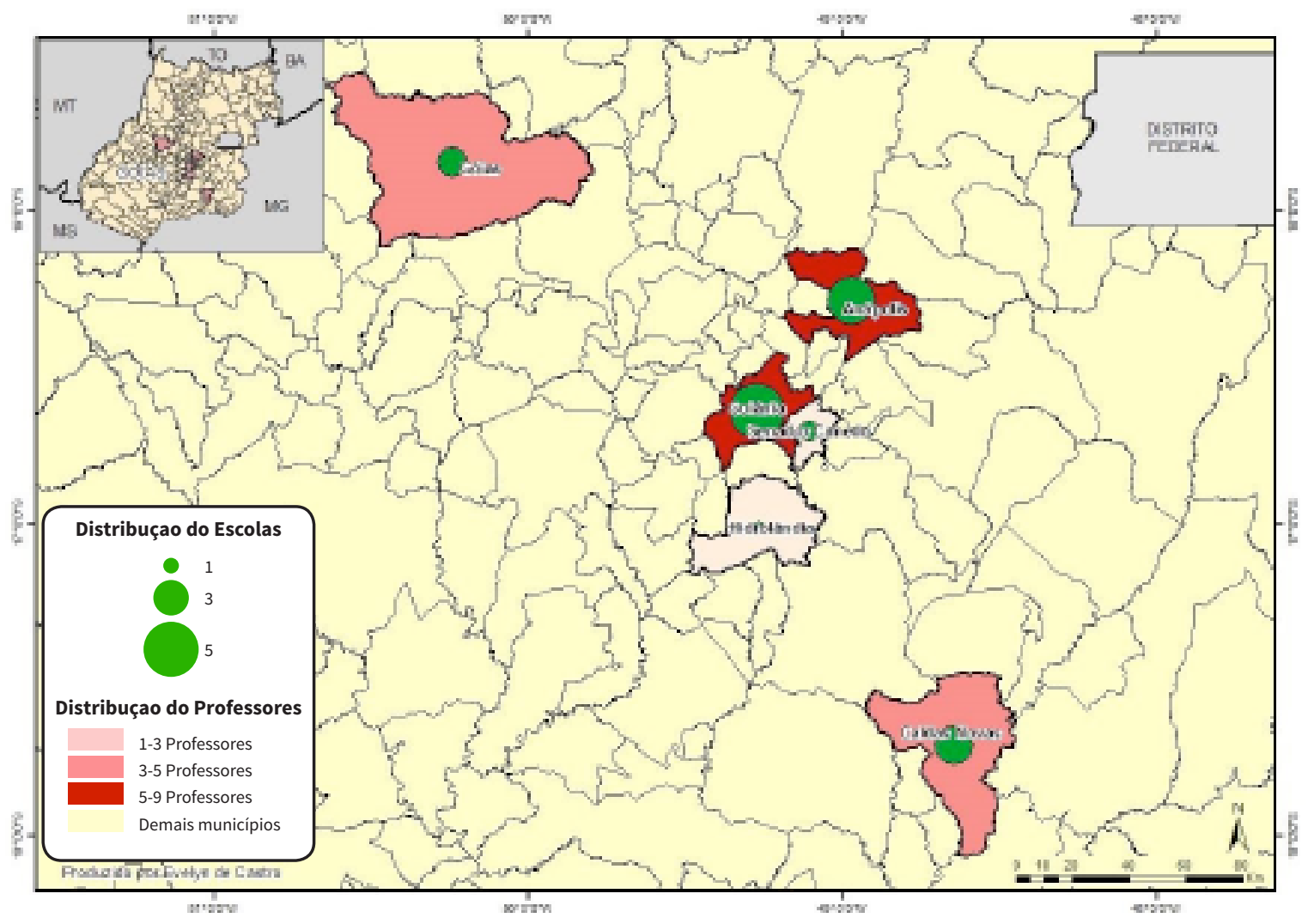

Figura 2. Distribuição de escolas dos professores entrevistados em Goiás, 2015-2016. 
da convivência diária na sala de aula. É na práxis cotidiana que vamos construindo nossos conceitos, nossas metodologias e nossas formas de pensar sobre os alunos e sobre o saber específico.

Portanto, com seus diferentes tempos de atuação profissional, os professores da pesquisa constituem uma parte do universo de docentes que colocam os currículos estaduais em ação em suas práticas didáticas cotidianas na escola. Assim, as concepções desses professores sobre a Geografia presente nos currículos são importantes referências a serem consideradas na análise curricular.

\section{A Geografia e os conteúdos segundo os docentes do Rio de Janeiro e de Goiás}

Qual é a importância da Geografia Escolar? Essa é uma das questões que permeiam a discussão sobre os motivos da permanência da disciplina de Geografia no currículo oficial de todos os estados, municípios e no currículo federal. Portanto, qual é o sentido e qual é a razão da obrigatoriedade de ensino dessa disciplina na escola?

De uma forma geral, a reflexão sobre o objetivo da Geografia na escola perpassa a necessidade de criar condições para a formação de uma consciência espacial cidadã, bem como a intenção de propiciar a realização da leitura do mundo por meio de diferentes categorias de análises geográfica e, ainda, a compreensão da espacialidade dos objetos e fenômenos estudados. 0 objetivo final é que o aluno forme uma consciência espacial, de um modo de pensar geográfico que compreenda o modo como a sociedade em sua relação social com a natureza cria e recria objetos para fins econômicos.

Os professores de Geografia que atuam na rede estadual de ensino do Rio de Janeiro trataram sobre esse assunto nos questionários. Identificaram-se, de forma geral, três elementos dominantes nas respostas dos docentes: 1) pensar a construção espacial do lugar onde vive; 2 ) construir a formação crítica do estudante; 3) compreender as múltiplas escalas. Esses elementos podem ser analisados a partir de algumas respostas apresentadas a seguir.

Para esses professores o ensino de Geografia tem como importância contribuir na formação cidadã dos estudantes, mostrando que essa disciplina tem sentido para sua vida, para as dinâmicas que acontecem à sua volta e, assim, poder agir e atuar de forma a saber fazer criticamente a leitura espacial.

PRJ1: Contribui para o pensamento crítico, pensar e entender as relações humanas e o trabalho modificam o espaço natural.

PRJ4: Estratégica de formar cidadãos conscientes de sua realidade e de seu papel na sociedade. Pensar o espaço onde ele vive, bem como compreender o mundo que o cerca.
PRJ5: Auxilia na formação do cidadão com consciência espacial, de cunho crítico e fornece ferramentas para que os sujeitos interpretem e analisem espacialmente os fenômenos sociais e ambientais.

PRJ9: Consciência da dimensão espacial do cotidiano. Práticas sociais de nossos alunos para sejam pensadas espacialmente. Pensamento crítico e autônomo.

PRJ12: Formação cidadã consciente e promover a compreensão da sociedade como sua base material em sua totalidade.

PRJ19: É por meio desta disciplina que podemos refletir sobre o espaço que vivemos, suas transformações e como podemos atuar para cuidar melhor deste espaço.

PRJ31: A Geografia na escola se faz importante, quando o processo ensino aprendizagem contribui para "se posicionar no mundo". Reconheço o saber geográfico como um instrumento de poder, que só faz sentido quando possibilita reconhecer nossa posição no mundo, para nele agir.

Para esses docentes, essa disciplina utiliza uma base conceitual que leva o aluno a compreender, por meio de suas práticas sociais e sua vida cotidiana, aquilo que vivenciam, para que tenham consciência e saibam interpretar o espaço e suas transformações tanto da sociedade quanto da natureza. Dessa maneira, a disciplina passa a ter um sentido social, já que é mediada também para compreensão do espaço vivido dos estudantes.

Outra questão geral apontada pelos professores sobre a importância da Geografia foi acerca do trabalho com as várias escalas de análise, seja local, regional, nacional e mundial.

PRJ8: Provocar através dos conhecimentos os alunos a pensarem e repensarem sobre sua passagem neste mundo, enquanto sujeito ativo, entender o mundo e a sociedade em que vive. Intervir nas mudanças e aos fenômenos que rotineiramente contribuem para a formação do espaço geográfico de modo crítico e reflexivo em diferentes escalas.

PRJ16: Serve para o aluno se localizar, identificar o mundo e as relações que são estabelecidas entre os diversos países.

PRJ20: Serve para fazer o aluno compreender como está inserido no mundo. Saindo do local para o mundial.

PRJ33: A principal função da Geografia na escola para mim é proporcionar meios para a construção de um olhar crítico e espacial acerca da realidade, ou seja, uma visão mais profunda, uma capacidade de produção e análise, tanto de questões próximas, quanto de questões distantes, com ressalvas ao termo crítico, e, do que é próximo e distante nos tempos atuais.

Os professores buscam compreender que a Geografia deve fazer com que o estudante saiba se localizar e identificar por meio da análise dos 
fenômenos que estão especializados no mundo em diferentes escalas de análise, permitindo, assim, que conheça não só seu lugar, mas também o mundo.

Por sua vez, os professores de Goiás analisaram que a Geografia deve fazer com que o estudante aprenda a se localizar e saiba identificar fenômenos em sua dimensão espacial em diferentes escalas de análise. Assim, os alunos terão a oportunidade de conhecer seu lugar e também o mundo.

Perceberam-se quatro características gerais nas respostas dos professores de Goiás quando trataram da importância do ensino de Geografia. A primeira característica está centrada na compreensão do conceito de espaço, conforme o posicionamento de seis professores. A segunda é marcada pelo ensino dos acontecimentos cotidianos, isto é, a importância da Geografia se dá em decorrência de ela ensinar os acontecimentos reais que ocorrem no período letivo escolar.

PGO2: Ensinar tudo o que é atual, o porquê dos acontecimentos.

PGO3: É importante porque abre a mente dos alunos para os acontecimentos do mundo.

PGO4: Acredito que é a disciplina mais familiar com o cotidiano dos alunos. Por meio da Geografia eles têm o conhecimento real do mundo. Por exemplo, se eu trabalhar questões rurais, urbanas, turísticas, mapeamento, posso utilizar as características reais da cidade para falar das teorias.

Por conseguinte, a disciplina trabalha com várias questões que contribuem para o conhecimento sobre os diferentes temas geográficos. Podemos dizer que os professores pensam a Geografia como uma forma de compreender o mundo atual, os acontecimentos do cotidiano, porque esta disciplina escolar apresenta o aqui e o agora. Logo, as temáticas relacionadas aos aspectos urbanos, rurais, entre outras, são destacadas como exemplos de temas cujos referenciais empíricos visíveis na realidade cotidiana dos estudantes podem ser utilizados na análise teórica feita na aula.

Em relação à terceira característica, os professores responderam que a formação crítica do cidadão é um dos elementos mais importantes para o ensino da Geografia.

PG05: Uma disciplina que contribui para a formação crítica de todo cidadão. Proporciona conhecimentos importantes do nosso planeta, como o clima, a vegetação, a hidrografia, o tempo atmosférico, e os aspectos sociais, econômicos e políticos.

PGO12: Fazer com que o aluno possa compreender a realidade que o cerca, identificando questões problemáticas e propondo soluções.

PGO13: A Geografia pode facilitar a construção e o desenvolvimento da cidadania, possibilitando aos alunos se localizarem nos planos físicos, culturais, econômicos e políticos.
PGO16: Despertar senso crítico, respeito ambiental, organizacional; noções de espaço local e sua imersão enquanto estudante, ou seja, a Geografia é fundamental para se formar um cidadão com preparo para entender o mundo e as relações que o cercam.

PGO43: Essa disciplina permite que o aluno desenvolva um olhar social mais amplo. Os conteúdos abordados nas aulas de Geografia permitem que os educandos se tornem pessoas mais críticas e menos alienadas. Porém, infelizmente é uma matéria que está, a cada dia, sendo desvalorizada. Segue-se uma lógica do capital

Uma das questões centrais para esses professores é que a Geografia contribui para que o estudante pense a sua realidade de forma crítica, para que ele tenha conhecimento dos problemas existentes no mundo, para compreender as relações que acontecem em seu cotidiano, como as dimensões física, econômica e política.

A quarta característica está ligada às questões ambientais e de escalas. Para os professores de Goiás, a Geografia proporciona uma discussão crítica sobre os fenômenos para que os estudantes possam saber ler e interpretá-los. Assim, um dos elementos importantes para o estudo da natureza é a abordagem dos aspectos sociais, econômicos e políticos. Nesse sentido, dois professores (PGO26 e PGO28) discutem a relação entre sociedade, ambiente e questões globais, entre o físico e o social.

PGO14: É a disciplina que ajuda na formação do indivíduo para entender a relação do ser humano com o espaço tanto local quanto global.

PGO15: Para levar o aluno a compreender o espaço vivido, suas transformações naturais, políticas, sociais e culturais; perceber as implicações que levam à organização do espaço global e as relações de poder mesmo; formar cidadãos críticos, conscientes e atuantes.

Observa-se a preocupação dos professores de ambos os estados com as escalas local e global para que o estudante consiga compreender as relações que ocorrem no espaço em suas diferentes escalas. Também destacam a importância da disciplina para formar cidadãos críticos e conscientes a partir da compreensão do conceito de espaço geográfico.

Quanto à questão se os conteúdos previstos no currículo são pertinentes ou não, os professores do Rio de Janeiro se dividiram em três grupos. Um acredita que não, o segundo grupo afirma que depende e o terceiro que responde afirmativamente à questão, mas apresenta algumas considerações.

No grupo dos professores que não considera o currículo pertinente, encontram-se as seguintes justificativas:

PRJ5: Não, pois aparecem de forma quase que estética, como descrição de alguma paisagem. 
PRJ10: São formulados de formas confusas, contraditórias e descontextualizas.

PRJ11: Não, porque o modo que se estrutura valoriza uma visão fragmentada da Geografia.

PRJ23: Não. Os conteúdos estão fora de ordem, ficando difícil o desenvolvimento do trabalho. Às vezes para dar conta da aprendizagem, acabo entrando em conteúdos que não estão naquela série, mas que são necessários.

PRJ27: Os conteúdos geográficos não estão presentes de forma integradora com a realidade do aluno, são abordados de forma pronta e acabada, sem reflexões sobre suas construções e representações no contexto social dos alunos.

Os professores que consideram não ter relação com os conteúdos apresentam três elementos: o primeiro ligado ao conceito de paisagem como visão estética da realidade, como era tratado esse conceito no século XIX, como uma mera descrição. $O$ segundo está relacionado ao padrão $\mathrm{N}-\mathrm{H}-\mathrm{E}$ (natureza, homem e economia) que, de acordo com Moreira (1987), perdura na discussão escolar. No terceiro, os conteúdos são apresentados de maneira confusa, não demonstrando coerência entre eles e são expostos de forma desconectada da realidade do estudante.

No grupo dos professores que considera o currículo pertinente em algumas situações, encontram-se as seguintes justificativas:

PRJ1: Parcialmente, nos anos finais do ensino fundamental não estão bem relacionados.

PRJ19: Alguns de forma bem resumida, outros de forma mais esclarecida.

[Nos anos finais aparecem os conteúdos relacionados à escala mundial, que estão focadas no padrão N-H-E, por isso, não estão bem-relacionados e são apresentados de forma resumida. No grupo dos professores que considera o currículo pertinente, mas acrescenta considerações, encontram-se as seguintes justificativas:

[PRJ4: Sim, mas temos que adaptar às diferentes realidades.

PRJ10: Sim, mas são muito generalistas. Não parte do vivido.

PRJ15: São sucintos, mas tenho a liberdade de praticar ou complementar o conteúdo que achar conveniente.

PRJ17: São pertinentes, mas poderiam ser melhores aplicados e diversificados.

PRJ28: Sim, só não gosto da ordem como aparecem, porém o currículo não é ruim, talvez um pouco descontextualizado.

Em praticamente todas as respostas positivas observa-se que os professores têm algo a comentar. Citam, por exemplo, que os conteúdos não partem do vivido do estudante, que estão muito longe da realidade, por isso há a necessidade de fazer adaptações. Esses, como são mínimos, não trazem uma diversidade de temas, abordam conteúdos presentes no currículo desde o século XIX com poucas alterações. Contudo, uma professora (PRJ 15) diz que tem liberdade para complementar aquilo que for necessário em sua aula. Esta complementação está prevista na Resolução SEEDUC nº 4.866 (2013) no parágrafo 40: “I - compete aos professores regentes declarar bimestralmente, no sistema Conexão Educação, as habilidades e competências desenvolvidas em suas turmas de suas respectivas disciplinas, bem como inserir observações sobre ajustes acerca da utilização do Currículo Mínimo."De acordo com a própria Resolução, o professor "pode" desenvolver o currículo da forma que seja mais coerente, respeitando as habilidades e competências já estabelecidas pelo Estado. Segundo vinte e nove professores de Goiás, os conteúdos geográficos presentes no currículo são coerentes, nove afirmam que não, cinco afirmam que são parcialmente e um não respondeu. Algumas respostas afirmativas foram:

PGO12: Sim, estão pertinentes dentro de uma perspectiva socioambiental. Cabe ressaltar que em relação ao ENEM fica a desejar.

PG014: O currículo é coerente com relação aos conteúdos, mas também não dá conta da totalidade. Por exemplo, não concordo em ensinar Goiás no $3^{\circ}$ ano do Ensino Médio, no $3^{\circ}$ bimestre. A principal preocupação é com o ENEM.

PG16: No caso do livro do aluno não, mas a proposta é conveniente.

PGO29: Sim, só não está de acordo com o livro. Os conteúdos não batem com o livro e não há em livros os conteúdos sobre a Geografia de Goiás.

Apesar de concordarem com os conteúdos, os professores colocam como exceção os temas previstos para o $3^{\circ}$ ano do Ensino Médio, porque consideram que eles não potencializam o ENEM. Outro argumento é de que não estão coerentes com os livros didáticos. Outro professor diz que os conteúdos não ajudam o estudante, pois são padronizados, e um terceiro professor afirma que, na maioria das vezes, falta uma correlação entre os conceitos de um ano para outro. Esses profissionais, apesar de analisarem que existe uma conveniência entre os conteúdos, referem também o fato de esses não se articularem com outros elementos.

É de se esperar que o currículo não seja totalmente favorável em algum momento. Por exemplo, não pode haver mesmo coerência com o livro didático, pois o processo de construção desse material não está relacionado ao currículo, e sim aos PCNs e aos parâmetros associados ao PNLD, além de o livro, na realidade, ser a obra de um determinado autor. Para um professor (PGO4) alguns conteúdos são excessivos, fazendo com que em algumas séries haja muitos conteúdos para pouco tempo de aula. Já para outro (PGO06), o problema é a falta de material para trabalhar. Outras falas contrárias à validade dos conteúdos contidos no currículo de Geografia em Goiás foram: 
PGO2: Não, porque estão sem sequência lógica de raciocínio. Porque para eu ensinar determinado conteúdo, eu preciso de uma "base", e talvez a base esteja após o conteúdo. Então está totalmente desconexo, não tem uma hierarquia lógica de aprendizagem.

PGO7: Não. Alguns bimestres têm muitos conteúdos e outros bimestres são limitados. 0 currículo tem ideias principais, não nos possibilitando acrescentar outras. Não concordo com a sequência também, ele engessa muito porque não tenho a opção de alterar nada. Mas apesar desses apontamentos, acredito que tenho autonomia para dissolver um pouco essa cobrança, e isso devido a minha formação, que me auxiliou a ter uma concepção mais crítica e autônoma sobre essas questões.

PGO13: Não, pois eles não atendem às expectativas dos alunos do meio rural, haja vista que o currículo promove um processo de padronização do saber.

PGO33: Não. Coloca partes do currículo do $6 .^{\circ}$ ano que não caberia, ou pelo menos como estão apresentadas.

Para esses professores, não existe uma lógica e uma hierarquia na sequência dos conteúdos, que são engessados e não permitem alterações. Um professor (PGO7), no entanto, argumenta que teria autonomia para tratar algumas questões mais específicas do currículo, pois a sua formação lhe possibilitou ser crítico e lhe ofereceu as condições para trabalhar com outras perspectivas além do que está no currículo.

Trabalhar o conteúdo na escola é, ao nosso entender, o meio para desenvolver a capacidade dos alunos na compreensão de sua realidade, por intermédio de um sistema organizado, com valores científicos e orientadores, que lhes proporcionará construir sua capacidade de ler o mundo a sua volta, estabelecer sua relação entre o próximo e distante, e compreender historicamente as suas transformações. A abordagem de conteúdos traz uma visão mais aberta da importância de cada um em sala de aula, bem como da forma como os professores desenvolverão o ensino desse conteúdo. Mas, ao pensar sobre isto, cada professor deve escolher como interpretará a realidade e quais elementos são necessários para a aprendizagem de seu aluno.

\section{Considerações finais}

sabendo-se que as reformas em torno do currículo não se estabelecem apenas na escala local, é necessário compreender as diferentes mediações escalares que a envolvem na perspectiva de entender o diálogo que tem sido estabelecido entre as políticas federais e as estaduais na organização da Educação Básica. Assim, os currículos do Rio de Janeiro e de Goiás foram criados a partir da estruturação dos PCNs, que direcionam a forma como os estados conduziram a produção de seus currículos, baseados em competências e habilidades, em bimestres, semestres e em anos.

Especificamente os currículos da disciplina de Geografia, tanto no Rio de Janeiro quanto no Estado de Goiás, foram construídos pela comunidade disciplinar, por uma equipe de professores universitários e da educação básica que têm características e concepções teórico-metodológicas diferentes. Destaque-se que em Goiás, ao que parece, houve maior participação dos professores da Educação Básica nesse processo de construção do que no Rio de Janeiro.

Quanto à abordagem da disciplina de Geografia no currículo, ela aparece como uma matéria dentro da estrutura curricular dos dois estados, nos ensinos Fundamental e Médio, contando, nesses níveis de ensino, com três e duas aulas respectivamente. Quanto aos conteúdos, embora parte considerável dos professores considere que estão adequados, há críticas contundentes acerca da forma como estão estruturados no currículo, não permitindo ao professor um trabalho mais consistente.

Para finalizar, é também fundamental desvendarmos os interesses escondidos atrás de discursos acerca da importância do currículo para garantir a igualdade de direitos entre todos. 0 currículo por si só não garantirá efetivamente a "igualdade", nem ao menos a redução das disparidades regionais no Brasil. Poderá sim submeter os estudantes a um projeto de reeducação e manipulação da aprendizagem para que esses tenham condições mínimas de trabalhar em empresas, garantindo a elas, além de uma mão de obra minimamente qualificada, um consumidor para seus produtos.

Some-se a isso o fato de estarmos avaliando currículos estabelecidos para atender a exigências que se constituíram nos anos 1990 e 2000, num momento em que as redes estaduais e municipais estão convidadas a participar do debate acerca da definição de um currículo assentado numa Base Nacional Comum Curricular. Como ficarão as indicações relativas à consecução de um currículo que atenda às necessidades locais? Em que medida haverá espaço para discussões acerca das múltiplas escalaridades dos fenômenos geográficos? Até que ponto essa Base Nacional Comum Curricular permitirá compreender a espacialidade dos fenômenos? Essas e outras questões deveriam ser objeto de preocupação dos profissionais em Geografia das diversas instâncias que são responsáveis pela construção e implementação do currículo. 


\section{Referências}

Callai, H. C., (2006) A articulação Teoria-prática na Formação do Professor de Geografia. Em: A. M. M. Silva, et al., Educação Formal e Não Formal, processos formativos e saberes pedagógicos: desafios para a inclusão social. (pp. 127-161). Rio de Janeiro: Alternativa.

Constituição da República Federativa do Brasil de 1988. (2001). [Coleção Saraiva de Legislação]. (21a ed.). São Paulo: Saraiva.

Cossio, M. de F., (2014). Base Comum Nacional: uma discussão para além do currículo. Revista e-Curriculum, 12(3), pp. $1570-1590$

Ferreira, W. A., (2009). O currículo de geografia: uma análise do documento de reorientação curricular da SEE-RJ. Dissertação de mestrado apresentado Pós-graduação em Geografia Humana. Departamento de Geografia/ FFLCH- USP, São Paulo.

Huberman, M., (1995). O ciclo de vida profissional dos professores. Em: A. Nóvoa, (Org). Vidas de professores. (2a ed, pp. 31-62). Porto: Porto.

Lei no 9.394, de 20 de dezembro de 1996. Estabelece as diretrizes e bases da educação nacional. Diário Oficial da União. Brasília, DF.

Lei nº 12.796, de 4 de abril de 2013. Altera a Lei no 9.394, de 20 de dezembro de 1996, que estabelece as diretrizes e bases da educação nacional, para dispor sobre a formação dos profissionais da educação e dar outras providências. Diário Oficial da União. Brasília, DF.

Lopes, A. C. \& Macedo, E., (2011) . Teorias do Currículo. São Paulo: Cortez.

Macedo, E., (2014). Base Nacional Curricular Comum: Novas formas de sociabilidade produzindo sentidos para educação. Revista e-Curriculum, 12(3), pp.1530- 1555.

Ministério da Educação, (2013). Diretrizes Curriculares Nacionais Gerais da Educação Básica. Brasília: Autor.

Moreira, A. F. B. \& Silva, T. T., (2001). Sociologia e Teoria crítica do currículo: uma introdução. Em: Currículo, cultura e sociedade. (5 ed, pp.7-36). São Paulo: Editora Cortez.

Moreira, R., (1987). O discurso do avesso (Para a crítica da Geografia que se ensina). (1a ed). Rio de Janeiro: Contexto.

Pereira, M. Z. C.; Santos, M. E. dos, \& Leite, J. C. P., (2012). O Campo das Políticas Curriculares no Brasil: a trajetória histórica da década de 90. Em: X Colóquio sobre Questões Curriculares/VI Colóquio Luso Brasileiro de Currículo: desafios contemporâneos no campo do currículo. Belo Horizonte, MG, Brasil.

Resolução SEEDUC N ${ }^{\circ}$ 4.866, de 14 de fevereiro de 2013. Dispõe sobre a implantação e acompanhamento do currículo mínimo a ser instituído na rede de ensino pública do Estado do Rio de Janeiro. Diário Oficial do Estado do Rio de Janeiro. Rio de Janeiro, RJ.

Sacramento, A. C. R.; Morais, E. M. B.; Oliveira, K. A. T. \& Moraes, L. B., (2015). Concepções e particulares dos currículos estaduais no Brasil: compreendendo a Geografia Escolar em Goiás, Rio de Janeiro e São Paulo. Em: VI EDIPE Encontro Estadual de Didática e Práticas de Ensino.(pp. 1-15). Goiânia: CEDEP.

Secretaria do Estado de Educação, (2013). Currículo Referência da Rede Estadual de Educação de Goiás. Goiânia: Autor. 